\title{
After Postmaterialism: An Essay on China, Russia and the United States: A COMMENT $^{1}$
}

\author{
RONALD F. INGLEHART
}

B rym's article in the current issue of this journal is an interesting and well-written discussion of an important topic and it presents a substantial body of evidence, addressing a theoretically significant question.

Unfortunately, Brym misinterprets the theory he seeks to refute. He implies that Inglehart's theory of intergenerational value change predicts that a trend toward Postmaterialist values and Self-expression values will always occur, regardless of economic and social conditions - interpreting evidence of any move in the opposite direction as refuting the theory. In fact, Inglehart has, from the start, argued that the intergenerational shift toward Postmaterialist values and Selfexpression values is driven by rising levels of existential security. If younger birth cohorts grow up under substantially higher levels of economic and physical security than their elders, this will produce a trend toward new values; and declining levels of existential security will have the opposite effect. The author even quotes Inglehart as saying: "The theory, of course, does not say that every country in the world is magically drawn in this direction. The theory is that if the population grows up under increasing security, then it is drawn in this direction. Russia's recent history, following the collapse of communism, was not rising security; it was declining security."

But, having quoted this statement, throughout the rest of his article, Brym treats Russia as a deviant case that undermines the theory. He justifies this interpretation by claiming that Russia has experienced almost a generation of rising economic security, making the astonishing claim that its economy grew by 999 percent from 1999 to 2013.

1. This article was supported by a subsidy to the HSE by the Russian Government's Global Competitiveness Program 
Table 1. Real per capita income in Russia, in constant (2005) U.S. \$, 1989-2015

\begin{tabular}{|c|c|}
\hline 1989 & $\$ 5,883$ \\
\hline 1990 & 5,865 \\
\hline 1991 & 5,386 \\
\hline 1992 & 4,601 \\
\hline 1993 & 4,207 \\
\hline 1994 & 3,683 \\
\hline 1995 & 3,529 \\
\hline 1996 & 3,407 \\
\hline 1997 & 3.461 \\
\hline 1998 & 3,282 \\
\hline 1999 & 3,504 \\
\hline 2000 & 3,870 \\
\hline 2001 & 4,085 \\
\hline 2002 & 4,298 \\
\hline 2003 & 4,633 \\
\hline 2004 & 4,985 \\
\hline 2005 & 5,324 \\
\hline 2006 & 5,776 \\
\hline 2007 & 6,280 \\
\hline 2008 & 6,612 \\
\hline 2009 & 6,093 \\
\hline 2010 & 6,363 \\
\hline 2011 & 6,361 \\
\hline 2012 & 6,845 \\
\hline 2013 & 6,922 \\
\hline 2014 & 6,844 \\
\hline 2015 & 6,487 \\
\hline
\end{tabular}

Source: World Bank statistics downloaded from

http://knoema.com/mhrzolg/gdp-statistics-from-the-worldbank? country $=$ Russian $\% 20$ Federation 
Figure 1: Real per capita income in Russia, in constant (2005) U.S. \$, 1989-2015

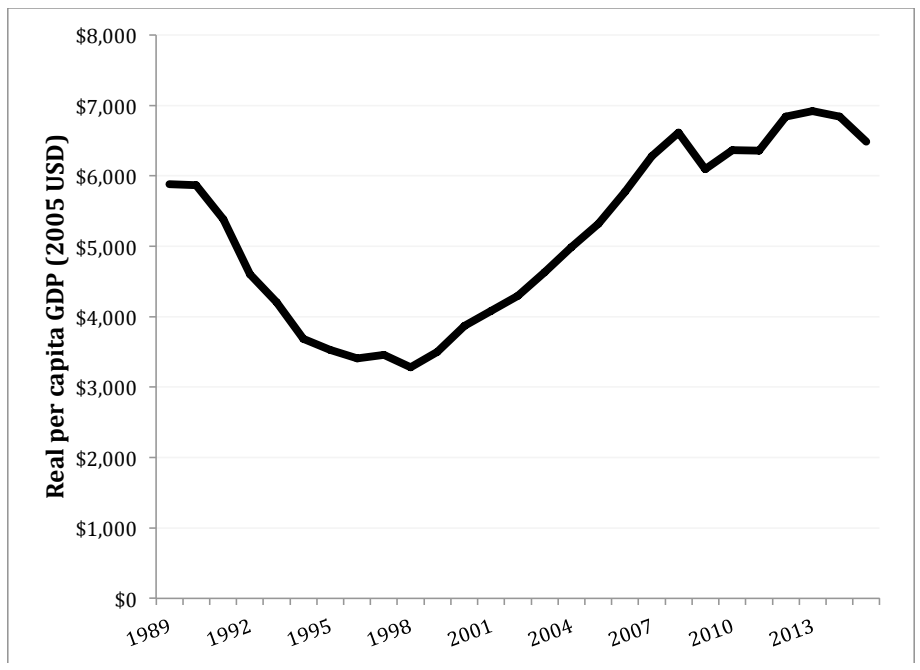

Source: World Bank statistics downloaded from

http://knoema.com/mhrzolg/gdp-statistics-from-the-worldbank? country $=$ Russian $\% 20$ Federation

This picture of the Russian economy as a dramatic success story is one that few economists would recognize. As Table 1 indicates, from 1989 to 2015, the Russian public experienced a severe economic decline that bottomed out in 1998, with some subsequent recovery. In 2015, real per capita income was 10 percent above its 1989 level. Does this imply that Postmaterialist values should now be 10 percent higher than in 1989. Of course not. For the collapse of communism brought not only economic decline, but the disintegration of the Soviet Union, the expansion of NATO to within 100 miles of St Petersburg, the breakdown of social services, rising crime, declining male life expectancy, sharply rising economic inequality and the collapse of a Marxist belief system that once brought a sense of meaning and purpose to millions of people. Though real per capita income is a fairly good indicator of existential security, it is only one component.

Moreover, Brym's assumption that recent economic growth should be immediately reflected in value change contradicts the theory he is seeking to refute. Inglehart's theory of intergenerational value change is based on two key hypotheses (Inglehart 1977): 
"1. A Scarcity Hypothesis. Virtually everyone aspires to freedom and autonomy, but people tend to place the highest value on the most pressing needs. Material sustenance and physical security are immediately linked with survival, and when they are scarce people give top priority to these "Materialistic" goals; but under conditions of prosperity, people become more likely to emphasize "Postmaterialist" goals such as belonging, esteem, and esthetic and intellectual satisfaction.

2. A Socialization Hypothesis. The relationship between material conditions and value priorities is not one of immediate adjustment: to a large extent, one's basic values reflect the conditions that prevailed during one's preadult years and these values change mainly through intergenerational population replacement."

Since the end of World War II, advanced industrial societies have diverged strikingly from previous history: most of their population has not grown up under conditions of hunger and economic insecurity. This has led to a shift in which needs for belonging, esteem and free choice have become more prominent. The scarcity hypothesis implies that prolonged periods of high prosperity encourages the spread of Postmaterialist values-- while enduring economic decline has the opposite effect.

But there is no one-to-one relationship between socioeconomic development and the prevalence of Postmaterialist values, for these values reflect one's subjective sense of security, which is partly shaped by a society's income level but also by its social welfare institutions and its security from violence and disease. Per capita income is one of the best readily-available indicators of the conditions leading to this value shift, but the theoretically crucial factor is one's sense of existential security.

The value change thesis was controversial from the start. Critics argued that the large age-difference found in 1970 reflected life-cycle effects rather than intergenerational change: young people naturally prefer Postmaterialist values such as participation and free speech, but as they matured, they would come to have the same Materialist preferences as their elders, so the values of society as a whole would not change (Boeltken and Jagodzinski, 1985).

The value change hypothesis, by contrast, holds that young people are more Postmaterialist than their elders only if they have grown up under substantially more secure living conditions. Consequently, we would not expect to find intergenerational value differences in stagnant societies, and if future generations no longer grew up under more 
secure conditions than their elders, we would no longer find intergenerational value differences. But the degree of security experienced during one's formative years has a lasting impact. Consequently, as relatively Post-materialist post-war birth cohorts replaced older, more Materialistic ones in the adult population, we should witness a shift from Materialist to Postmaterialist values.

A massive body of evidence demonstrates that an intergenerational shift from Materialist to Postmaterialist priorities has been occurring. But this is only one aspect of a broader cultural shift from Survival values, which give top priority to the survival needs, to Selfexpression values emphasizing gender equality, environmental protection, tolerance, interpersonal trust and free choice. It also includes a shift from emphasis on hard work toward emphasis on imagination and tolerance as important values to teach a child

Moreover, as the socialization hypothesis claims, people's basic value priorities do not change overnight. One of the most pervasive concepts in social science is that one's basic personality structure crystallizes by the time one reaches adulthood. Considerable evidence indicates that people's basic values are largely fixed when they reach adulthood, and change relatively little thereafter (Rokeach, 1968; Inglehart, 1977, 1997). If so, we would expect to find substantial differences between the values of young and old in societies that have experienced a rising sense of security. Intergenerational value change occurs when younger generations grow up under different conditions from those that shaped earlier generations.

This theory mainly concerns an intergenerational value change that occurs with long time lags, as younger generations replace older ones. Any definitive test of this thesis requires analyzing a long time series of extending over a period of several decades. Inglehart (2008) carried out such an analysis, finding that - although there were significant short-term fluctuations reflecting period effects linked with current conditions-- over a period of almost 40 years, as younger birth cohorts gradually replaced older ones in the adult population, they produced a shift from a 4:1 preponderance of Materialists over Postmaterialists in his six-nation West European sample in 1970, to a slight preponderance of Postmaterialists over Materialists in 2006. 


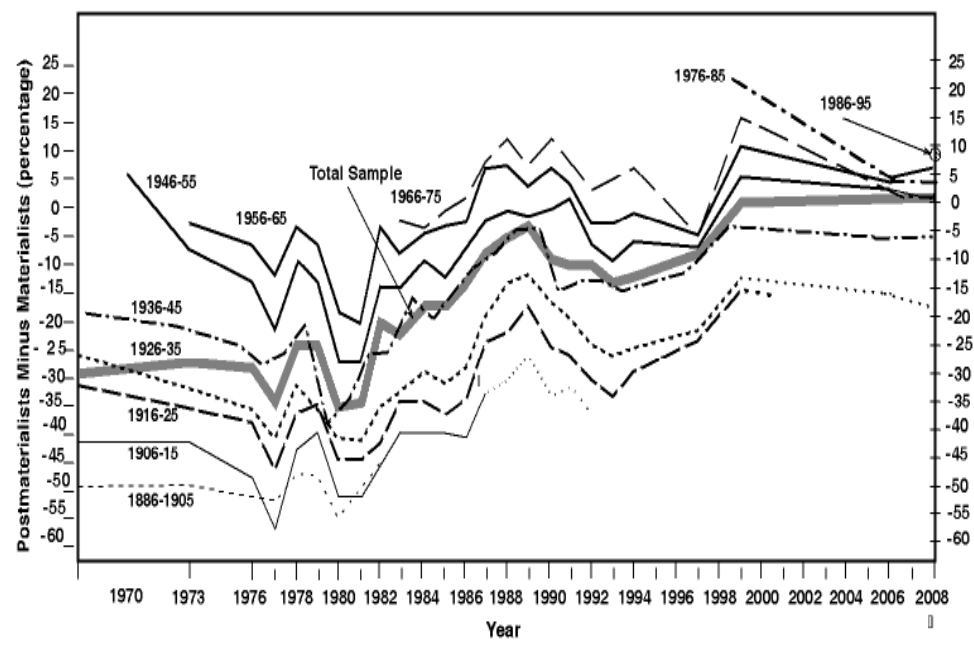

Figure 2: Percentage of Postmaterialists minus the percentage of Materialists in Six West European countries, 1970-71 to 2009, by Birth Cohort.

Based on weighted samples from Britain, France, West Germany, Italy, The Netherlands and Belgium.

Results from 1970 through 1997 are based on Euro-barometer surveys' results from 1999, 2006 and 2008-2009 are based on data from the World Values Survey and European Values Study.

The shift toward Postmaterialist values, we argue, is driven by the change from growing up with the feeling that survival is precarious, to growing up with the feeling that survival can be taken for granted. Although the older birth cohorts had experienced the slaughter and starvation of two World Wars and the Great Depression, the postwar birth cohorts in Western democracies grew up in prosperity, with welfare states reinforcing the feeling that survival was secure, during the longest period in history without war between major powers.

These differences between the formative experiences of the postwar birth cohorts and all older cohorts, produced major differences in their value priorities. But these differences started to become evident only when the first post-war birth cohort became politically-relevant young adults two decades after World War II, contributing to the era of Student Protest in the late 1960s and 1970s. A widespread slogan among the protesters was "Don't trust anyone over thirty!" At that time, the 
postwar cohort was still a small minority of the adult population. But as time went by, the 20 -year-olds became 30 -year-olds and eventually 40 -year-olds and 50-year-olds, transforming the values of their society as a whole. In 1970, Materialists outnumbered Postmaterialists by four to one in these six nations as a whole; by 2000 , Postmaterialists outnumbered Materialists.

At the earliest time point in 1970, there was a very large difference between the values of the youngest birth cohort-who had grown up during the postwar economic miracles and welfare states-- and all of the older cohorts, who had experienced World War I, the Great Depression and World War II during their pre-adult years. But by the 1980s, the postwar economic miracles had given way to economic stagnation and high unemployment especially among youth, so there no longer were large differences between the formative experiences of younger and older generations, and the pace of intergenerational value began to slow down - as the value change thesis predicts.

This theory holds that short-term period effects will also occur, and that they should move in the same direction as intergenerational change, with high levels of existential security being conducive to Postmaterialist and Self-expression values, and low levels having the opposite effect. As Figure 2 demonstrates, such period effects do appear, causing all birth cohorts to move up or down in response to favorable or unfavorable conditions. But in the long run, thee positive and negative fluctuations tend to cancel each other out, so that change is mainly due to intergenerational population replacement.

Brym assumes that changes in prevailing values will occur immediately after economic growth-- ignoring one of the theory's two most central points: that such changes will occur mainly through intergenerational population replacement.

Inglehart does not claim that Postmaterialist values (and Self-expression values) will always increase for some mysterious reason; he claims that when a large segment of the population grows up under high levels of existential security, they will tend to take survival for granted and give top priority to Postmaterialist and Self-expression values. High levels of economic and physical security (not high growth rates, which are most likely to be found in low-income countries) are conducive to these new values.

Brym misses this point when he argues that China-which has indeed experienced high rates of economic growth in recent decadesshould manifest high levels of Postmaterialist and Self-expression values. The fact that Postmaterialists are very scarce in China is exactly what the theory predicts. Until a few decades ago, most Chinese lived 
just above the subsistence level, and within the memory of living Chinese, at least 30 million Chinese starved to death in the aftermath of the failure of the Great Leap Forward: the Chinese public has not grown up taking survival for granted. The fact that China has also experienced a spectacular increase in economic inequality, moving from one of the world's most egalitarian income distributions under Mao, to having an even higher level of inequality than the U.S., also undermines the effect of overall economic growth: though some Chinese are billionaires, hundreds of million still live in poverty.

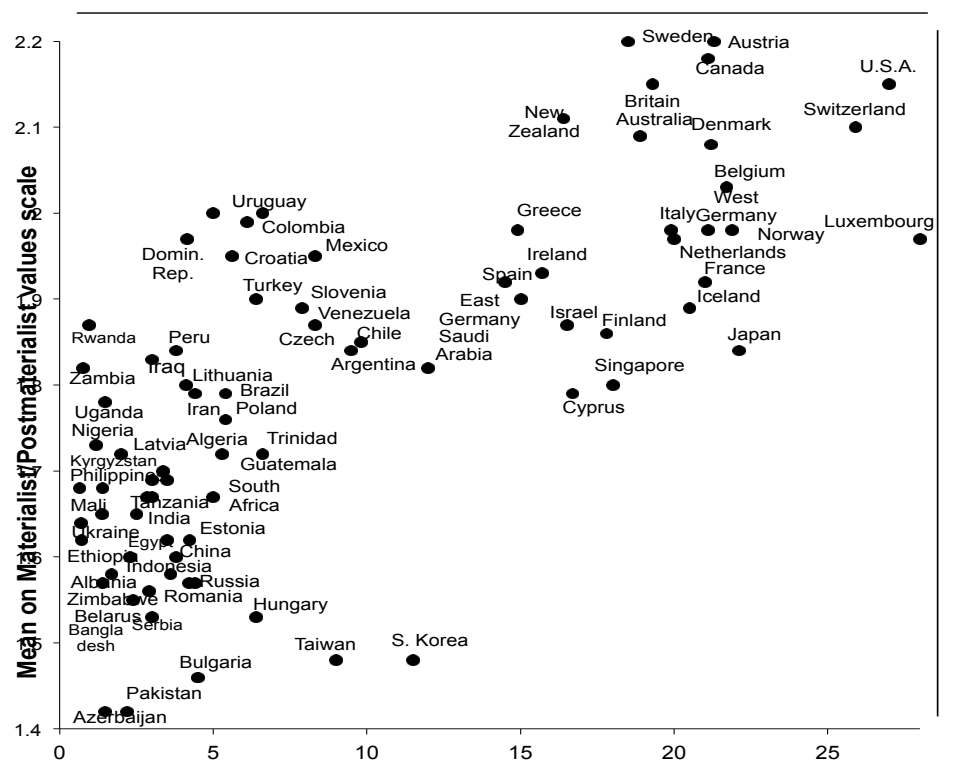

Figure 3: Materialist/Postmaterialist values by GNP/capita

$1=100 \%$ Materialist, $2=$ Materialist and Postmaterialist evenly balanced, $3=100 \%$ Postmaterialist

\section{GNP per capita in thousands, 1995 (PPP estimates) $r=.64$}

The shift to Postmaterialist and Self-expression values is not caused by high recent economic growth rates. It begins when a society attains the threshold where a sufficiently high level of existential security that younger birth cohorts grow up taking survival for granted. The countries in Figure 3 contain over 90 percent of the world's population-- and within this worldwide sample, we find a reasonably close fit between Postmaterialist values, and high levels of per capita income, 
as this figure demonstrates. Reflecting the long time-lag between economic development and the transformation of a society's values, this graph uses a society's per capita GDP in 1995 as a predictor of its values in the latest available survey

On Figure 3, the U.S. shows one of the highest levels of Postmaterialist values of any country in the world (along with Switzerland, Sweden, Austria and Canada), as its 1995 economic level would predict. Conversely, both Russia and China show low levels of Postmaterialist values - as their 1995 economic levels also predict. For the world as a whole, we find a .65 correlation between per capita GDP and the proportion of Postmaterialists. If we were to run a graph showing the linkage between values and recent economic growth rates, we would actually find a negative correlation, reflecting the fact that in recent decades, low-income and middle-income countries have experienced higher growth rates than high-income countries. The assumption that high recent growth rates immediately bring high levels of Postmaterialism, is misguided.

Brym's attempt to analyze the broader shift from Survival values to Self-expression values in China fails to distinguish between basic values and attitudes. Without attempting to determine whether given variables actually tap basic values, he simply declares that three questions from the Chinese General Social Survey tap Survival vs Selfexpression values. The face validity of these indicators is mixed, and Brym find mixed results. Moreover, he has no time series data for these items - he simply examines the demographic correlates of these items, again finding mixed results. I see little point in discussing this section any farther.

Although the U.S. public has shown a strong overall shift toward Postmaterialist values since 1972, these values have declined somewhat in recent years. Brym points out some of the reasons for this decline: though the U.S. has experienced economic growth in recent years, virtually all of the gains have gone to the top one percent: median real incomes have been stagnant and have actually declined for most of the public. Moreover, as he points out, the U.S. position on the world stage has become less secure and "the U.S. has responded to its growing sense of threat and declining power by seeking to shore up its security..." I agree with these claims - the world is indeed experiencing rising inequality and international tensions, both of which tend to undermine feelings of existential security - and I see no contradiction with my theory. I am simply puzzled by Brym's assumption that my theory holds that Postmaterialist values will always increase, regard- 
less of whether existential security is high or low-and consequently, that any evidence of declining security contradicts the theory.

Brym's article presents some interesting findings - many of which are exactly what my theory implies, but are interpreted as contradicting it. Brym's key error lies in assuming that value changes will occur immediately after economic events - although my theory clearly holds that basic values change entails a multi-decade time-lag since it occurs mainly through intergenerational population replacement-- and a massive body of evidence supports this claim. Consequently I find Brym's claim to have refuted the theory to be unconvincing.

\section{REFERENCES}

Boeltken, F. and W. Jagodzinski, 1985. "In an Environment of Insecurity: Postmaterialism in the European Community, 1970-1980." Comparative Political Studies 17: 453-484.

Brym, R."After Postmaterialism: An Essay on China, Russia and the United States." Canadian Journal of Sociology

Inglehart, R., 1977. The Silent Revolution: Changing Values and Political Styles among Western Publics. Princeton: Princeton University Press.

Inglehart, R. 1997.Modernization and Postmodernization: Cultural, Economic and Political Change in 43 Societies. Princeton: Princeton University Press.

Inglehart, R. 2008. "Changing Values among Western Publics, 1970-2006: Postmaterialist Values and the Shift from Survival Values to Self-Expression Values," West European Politics 31(1-2): 130-46.

Inglehart, R. and C. Welzel, 2005.Modernization, Cultural Change and Democracy: The Human Development Sequence. New York: Cambridge University Press.

Rokeach, Milton, 1968. Beliefs, Attitudes and Values. San Francisco: JosseyBass, Inc.

Ronald F. Inglehart (University of Michigan and Higher School of Economics, Moscow and St. Petersburg) Dr. Inglehart's research focuses on cultural change and its consequences. Using World Values survey data from 78 countries, he has investigated linkages between the values and beliefs of mass publics and the presence or absence of democratic institutions. He studies how cultural transitions in industrial societies influence individual autonomy and self-expression, politics, motivation to work, sexual and religious norms, and other central society and political orientations.

Email: $\underline{\text { RFI@umich.edu }}$ 